\title{
INDIVIDUAL KIT FOR IMMEDIATE DECONTAMINATION
}

\author{
Gabriel EPURE*, Dănuţ MOŞTEANU**, \\ Liliana RECE*, Ovidiu IORGA*
*Scientific Research Center for CBRN Defense and Ecology, Bucharest, Romania, * "Nicolae Bălcescu" Land Forces Academy, Sibiu, Romania \\ gabriel.epure@nbce.ro
}

\begin{abstract}
In case of CBRN incidents, the individual decontamination is an extremely urgent measure, for the rescue of personnel from all categories of military forces or from specialized intervention teams, as well as the civilian population unprotected or with minimal protection. Any delay has a significant impact on the fulfillment of combat missions, volume of losses and success of recovery. In this context, it must be considered the possibility that your own troops operate in areas with CBRN risk. The activities with top priority are those relating to the individual protection and immediate decontamination of the personnel, within a very short time, guaranteeing the chances of survival. The paper presents the research results of a multidisciplinary team in the decontamination of chemical, biological and radiological domain for achieving a new individual kit for immediate decontamination, according with the NATO required standards. In the paper the performance and technical-tactical features of the product are iterated, as well as the aspects related to the testing and evaluation of the product development.
\end{abstract}

\section{Keywords: CBRN, individual kit, immediate decontamination}

\section{Introduction}

The CBRN risks and threats are generated by:

- uncontrolled proliferation and dissemination of CBRN technologies and means of mass destruction and of unconventional lethal means;

- the existence of objectives (areas) with nuclear, biological and chemical risk;

- the expansion of terrorist networks and activities with the use of biological, chemicals agents and radioactive materials, which are threatening public safety, infrastructure and the environment;

- the cross-border trafficking of chemical, biological and radioactive materials.

All these threats require
implementation of measures for
prevention, personal protection and
removing the consequences of such
contamination.

In this context, among the activities with top priority there also exist those relating to individual protection and immediate decontamination of personnel, helping to overcome the effects of CBRN agents in a very short time, guaranteeing chances of survival.

Skin decontamination is an extremely urgent measure in order to save military personnel from all categories of military forces or from specialized intervention teams, as well as to protect the civilian unprotected population or with minimum protection. Any delay has a significant impact on the fulfillment of 
combat missions, volume of losses and success of recovery.

Chemical decontamination of the skin is required to be done within two minutes after exposure and it represents an immediate action that can make the difference between survival and death, being considered a vital health measure, similar with the administration of the antidote for survival.

\section{Destination}

The individual immediate decontamination kit (TIDI) is intended for all categories of military personnel from military forces, to lead and sustain operations in an environment that is presumed to be CBRN contaminated. The product provides chemical, biological and radiological decontamination of discovered surfaces of the body, equipment, weapons and materials of basic necessities which are in the endowment of the combatant personnel.

\section{The kit description}

The product is based on a solution of amino alcohols with a polyvalent decontamination effect, used both for skin decontamination and decontamination of portions affected from the equipment and weapons which are in the endowment of the military. The solution is impregnated on an inert chemically support, absorbent, non-woven fiber cloth type and packed in aluminized foil sachet in order to preserve the characteristics, the protection against solar radiation, sudden temperature changes and the contact with the air. The kit contains two such sachets, one for skin decontamination, the other for protective equipment and individual gear decontamination.

In the structure of the kit are also present two packets with sterile gauze which are used as, one for cleaning the contaminated skin with micro droplets of ACR, before using the cloth moistened with decontamination solution and the second one, for cleaning skin after decontamination operation with the moistened cloth.

To protect the hands during the decontamination process of the equipment, the kit comes with a pair of nitrile rubber gloves.

The skin decontamination is followed by the fitting of protective gloves, after this it takes places the decontamination of equipment, which is made directly by wiping with cloth soaked the contaminated portions with visible ACR micro droplets.

For rapid removal of the film decontamination solution from the protective equipment and armament, the kit is provided with a polyethylene bottle which contains a dose of active charcoal powder with high absorption capacity, which is easily pulverized in the wetted portions. It passes easily with the protected hand by the gloves over these portions to distribute uniform the powder all over the decontaminated surface.

The kit also contains zipper bags to collect the contaminated waste.

All kit components are packed in a bag with zipper aluminum laminate with polyethylene terephthalate and polyethylene, provided with ply at base (stand up type) for easy storage and handling.

The kit provides the decontamination of a surface of $0.25 \mathrm{~m}^{2}$ of discovered skin surfaces and $0.25 \mathrm{~m}^{2}$ of the protection equipment surface.

The consumption norm of decontamination solution is $120 \mathrm{ml} / \mathrm{m}^{2}$.

The two nonwoven fiber cloths soaked each with a maximum of $35 \mathrm{ml}$ remediation, provides the decontamination for a single person to a decontamination cycle.

The handling of the kit is very easy, requiring a short-term training, without implying specialist knowledge. It requires short time for training and operation and minimal maintenance.

In development of the product it was taken into account the fulfillment of 
operational requirements of standard AEP-58.

$\checkmark$ consumption norm for adsorbent active charcoal: $200 \mathrm{~g} / \mathrm{m}^{2}$;

Table 1. Performance features

\begin{tabular}{|c|c|c|}
\hline & FEATURES & $\begin{array}{l}\text { Requirements } \\
\text { According to } \\
\text { AEP } 58[1]\end{array}$ \\
\hline 1 & $\begin{array}{l}\text { Residual contamination after chemical } \\
\text { decontamination } \\
\begin{aligned} \text { - Yperite } \\
\text { - Soman } \\
\text { - Vx }\end{aligned}\end{array}$ & $\begin{array}{l}0,1 \mathrm{mg} / 10 \mathrm{~cm}^{2} \\
0,015 \mathrm{mg} / 10 \mathrm{~cm}^{2} \\
0,01 \mathrm{mg} / 10 \mathrm{~cm}^{2}\end{array}$ \\
\hline 2 & $\begin{array}{l}\text { Residual contamination after biological } \\
\text { decontamination }\end{array}$ & $\begin{array}{l}\text { Under } \\
10^{3} \mathrm{UFC} / \mathrm{m}^{2}\end{array}$ \\
\hline 3 & Radioactive decontamination efficiency & $\min .90 \%$ \\
\hline 4 & $\begin{aligned} \text { Minimum decontaminated surface with one chal ge } \\
- \text { On uncovered body parts }\left(\mathrm{m}^{2}\right) \\
- \text { On equipment }\left(\mathrm{m}^{2}\right) \\
\end{aligned}$ & $\begin{array}{l}0,25 \\
0,25 \\
\end{array}$ \\
\hline 5 & Preparationtime for use (seconds) & 10 \\
\hline 6 & $\begin{array}{l}\text { Neutralization time for chemical andra diological } \\
\text { agents (minutes) } \\
\begin{array}{l}- \text { skin } \\
- \text { equipment }\end{array}\end{array}$ & $\begin{array}{r}2 \\
10\end{array}$ \\
\hline 7 & Neutralization time for biological agents (minutes) & 10 \\
\hline 8 & $\begin{array}{l}\text { Temperature range for storage and transportation, } \\
\left({ }^{\circ} \mathrm{C}\right)\end{array}$ & $-33 \div+49$ \\
\hline
\end{tabular}

\section{Testing the performance features,} results and discussions

The product has gone through a complex testing program inside the center of scientific research for CBRN defense and the center for military medicine scientific research.

4.1 The determination of surface residual contamination with ACR (HD, GD, Vx)

Testing conditions:

$\checkmark \quad$ contamination norm with ACR $5 \mathrm{~g} / \mathrm{m}^{2}$; consumption norm for decontaminating: $120 \mathrm{ml}$; $\checkmark \quad$ decontaminator action time: skin-2 minutes, equipment- 10 minutes; $\checkmark \quad$ metal, rubber, polycarbonate, BC/SP2 samples; $\checkmark \quad$ decontaminated surface: 10 $\mathrm{cm}^{2}$

$\checkmark \quad$ solvent: methylene chloride; $\checkmark \quad$ equipment: GC system coupled with DSQ II mass spectrometer.

Procedure: In a square dish with glass cap it is introduced the surface sample for testing, it is contaminated with $5 \mathrm{mg}$ of ACR with known purity, as microdroplets. It is applied the specific decontamination procedure and we let the decontaminator in contact with surface. 
After 2 minutes in case of skin and 10 minutes in case of equipment, the reaction is faded by pipetting in the contamination dish $10 \mathrm{ml}$ of solvent over the surface sample. After 2 minutes of agitation, it is taken $1 \mathrm{ml}$ extract in a vial and analyzed with GC-MS. It is injected $1 \mu \mathrm{l}$ from each remanent toxic sample that needs to be analyzed. The retention times are determined and the areas of ACR signal.

Results: the vitro tests have highlighted that in all samples, the results obtained were according to standards requirements, under the imposed values, during the time imposed by the standard.

\subsection{Checking the efficiency of radiological decontamination}

Testing conditions:

- synthetic skin, metal, rubber, polycarbonate, $\mathrm{BC} / \mathrm{SP} 2$ samples;

- contamination norm with alpha, beta and gamma radio nuclides ( standard solution of $\mathrm{Cs}^{137}, \mathrm{Am}^{241}, \mathrm{Sr}^{90}$ ): $50 \mathrm{~Bq} / \mathrm{cm}^{2}$;

- consumption norm for decontaminating $120 \mathrm{ml}$ : $(124,8 \mathrm{~g}) / \mathrm{m}^{2}$;

- consumption norm for adsorbent active charcoal: $200 \mathrm{~g} / \mathrm{m}^{2}$;

- decontaminator action time on the surface samples: 10 minutes; $\mathrm{cm}^{2}$

- decontaminated surface: 10

- equipment: radiation monitor Berthold LB 123 with specific probes for alpha, beta and gamma decay.

Procedure: Contamination with radioactive solutions is performed on surface samples with dimensions of 10 $\mathrm{cm}^{2}$, according to AEP-58 standard, after which is measured the initial radioactive contamination $\left(\mathrm{C}_{\mathrm{i}}\right.$ în $\left.\mathrm{Bq} / \mathrm{cm}^{2}\right)$ with the help of radiation monitor. The specific procedure for decontamination is applied, after which the final radioactive contamination $\left(\mathrm{C}_{\mathrm{f}}\right.$ in $\left.\mathrm{Bq} / \mathrm{cm}^{2}\right)$ is measured.

Results: The value ranges obtained for the three types of radio nuclides used in testing on 5 types on materials is 90 to 98 percent, according to the requirements.

\subsection{Determination of residual contamination after biological decontamination}

Testing conditions:

- bacteriological strains Bacillus anthracis (bacterial spores and vegetative form);

- metal, rubber, polycarbonate, $\mathrm{BC} / \mathrm{SP} 2$ samples;

- contamination norm with $\mathrm{AB}$ : $10^{9} \mathrm{UFC} / \mathrm{m}^{2}$

- consumption norm for decontaminating: $120 \mathrm{ml}$;

- consumption norm for adsorbent active charcoal: $200 \mathrm{~g} / \mathrm{m}^{2}$;

- decontaminator action time on surfaces: 10 minutes;

- decontaminated surface: 10 $\mathrm{cm}^{2}$

- equipment: Incubator, specific crop environment.

Procedure: Before contaminating the surfaces, the initial (natural) contamination of the surfaces used for testing is checked, by harvesting samples through sweeping with sterile tampon, moistened with saline solution, on the 10 $\mathrm{cm}^{2}$ surfaces.

Contamination of the testing surfaces is realized through sweeping with the specific bacteriological suspension, after which is realized the contamination control through the technical adjustment TIS, through sweeping with sterile tampon, moistened with saline, on a $10 \mathrm{~cm}^{2}$ surface and the seeding on solid crop environment. To verify the contamination, the units that form colonies on the solid crop environment surface $\left(\mathrm{UFC} / \mathrm{cm}^{2}\right)$ is evaluated.

Decontamination procedure is applied, and at ten minutes the reaction it is stopped and continues the specific procedure (sweeping surfaces with a sterile swab, seeding culture media, incubation and analysis of these).

Results: At biological decontamination efficiency tests conducted on spores of B. anthrax and B. anthrax 
vegetative form, in conformity with AEP 58 , the results were compliant.

4.4. Testing the effectiveness of the chemical decontamination of the skin on test animals

Testing conditions:

contamination norm with ACR:

2LD ${ }_{50}$ Soman/ Mustard/Vx; consumption norm for decontaminant: $120 \mathrm{ml}(124,8 \mathrm{~g}) / \mathrm{m}^{2}$;

- Action time of the decontaminant - 2 minutes;

$\rightarrow$ decontaminated surface $-10 \mathrm{~cm}^{2}$; Procedure:

It works with laboratory animals (male Wistar rats weighing about $150 \mathrm{~g}$ ) distributed into homogenous groups.

Each toxic (Soman, VX, mustard gas) is applied using a micropipette piston percutaneously in appropriate volumes for 2 LD50 on a surface skin intact, freshly shaved on the back of the animal.

In maximum a minute from contamination it runs the chemical decontamination procedure; in 60 minutes after intoxication $0.5 \mathrm{ml}$ blood is collected for determination of acetyl cholinesterase.

The mortality and signs of intoxication (salivation, convulsions, respiratory failure 60 minutes and 24 hours) are tracked and recorded.

\section{Results:}

The tests of chemical skin decontamination efficiency contaminated with Soman and Vx showed cholinesterase inhibition below $40 \%$ and the decontamination of mustard gas injuries were minimal, resolved without treatment, in compliance with the standards.
4.5. Ocular tolerance checking of decontamination solution

Procedure:

The testing is carried out on rabbits weighing about $2 \mathrm{~kg}$ by applying the decontamination solution on the right eye, letting to act two minutes and then rinse-off.

In the left eye apply saline solution, leave for two minutes for action, then rinse-off; after 24, 48, 72 hours and for 7 days the occurred lesions were quantified.

\section{Results:}

The ocular tolerance checking tests of remediation solution demonstrated that the injuries were minimal, resolved without treatment.

\section{Conclusions}

The kit has been developed and certified according to the standards in force, covering a comprehensive testing program.

The experiments have shown the correctness of the technical solution adopted, as demonstrated in the test.

Our main objective for this year is to replace the actual decontamination kit with the newly developed TIDI.

In this regard, we must:

- cover the operational testing of the product at Training Base for CBRN defense Câmpulung Muscel;

- covering the ACF and AOO steps for the approval of the kit;

- listing TIDI in the endowment catalog of the Army.

\section{References}

[1] AEP 58 - Operational features, technical specifications, test procedures and assessment criteria for CBRN defense equipment. 